\title{
High-temperature synthesis of finely dispersed oxide materials and C12A7:e electrides in carbon nanoreactor conditions
}

\author{
A. M. Volodin, A. F. Bedilo, V. O. Stoyanovskii, V. I. Zaikovskii \\ Boreskov Institute of Catalysis, Prospekt Lavrentieva, 5, Novosibirsk, 630090, Russia \\ volodin@catalysis.ru
}

DOI 10.17586/2220-8054-2018-9-4-558-567

\begin{abstract}
Solid-state transformations of the oxide core in core-shell structures Oxide@C consisting of oxide nanoparticles covered with a carbon coating were studied at temperatures of up to $1500{ }^{\circ} \mathrm{C}$. It is shown that such coating can stabilize the size of the oxide core nanoparticles for alumina, zirconia, calcium and lanthanum aluminates and act as a shell of a nanoreactor where phase and chemical transformation can take place. For $\mathrm{ZrO}_{2} @ \mathrm{C}$ and $\mathrm{Al}_{2} \mathrm{O}_{3} @ \mathrm{C}$ it is demonstrated that it is the preservation of the small particle size that accounts for the preservation of cubic $\mathrm{ZrO}_{2}$ and $\delta-\mathrm{Al}_{2} \mathrm{O}_{3}$ until the carbothermal reduction temperatures of the corresponding oxides (above $1400{ }^{\circ} \mathrm{C}$ for $\mathrm{Al}_{2} \mathrm{O}_{3}$ ). The electride state C12A7:e is shown to be formed in C12A7@C material at temperatures above its melting point. The surface of activated C12A7 was found to have a significant concentration of active $\mathrm{OH}$ radicals capable of converting diphenylamine into stable nitroxyl radicals.
\end{abstract}

Keywords: Core-shell, nanocrystalline oxide, electride, $\mathrm{ZrO}_{2}, \mathrm{Al}_{2} \mathrm{O}_{3}$, carbon nanoreactor.

Received: 9 June 2018

Revised: 10 July 2018

\section{Introduction}

Core-shell structures with different chemical composition are widely used as nanoreactors in modern chemical studies [1-6]. The main goals for design of such materials are the formation of optimal conditions for operation of the core materials that do not depend on the external conditions, preservation of the core composition and size, performing selective chemical reactions with participation of the core using reagents penetrating through the shell, etc. It is obvious that the choice of the core and shell materials depends on their role and the range of operation conditions. In most cases, such systems are used either for reactions carried out in the liquid phase or in catalytic reactions taking place in the gas phase at moderate temperatures. The shells for catalysts operating at relatively high temperatures are commonly made of either $\mathrm{SiO}_{2}[1,2,6]$ or carbon [3-5].

Carbon-coated nanocrystalline $\mathrm{MgO}$ was shown to preserve the small particle size and have superior reactivity in decomposition of chlorinated compounds [7,8]. In our recent papers [9-12] it was demonstrated that the carbon coating in Oxide@C core-shell structures can function as a relatively solid nanoreactor shell, which is permeable to molecules from the gas phase and stabilizes the size of the oxide core at high temperatures.

A natural condition that limits this temperature range is the temperature of the oxide core carbothermal reduction, which depends on its composition. For aluminum-containing oxide systems studied by us $\left(\mathrm{Al}_{2} \mathrm{O}_{3}\right.$, calcium and lanthanum aluminates) this temperature exceeds $1400{ }^{\circ} \mathrm{C}$. So, the synthesis of core-shell particles makes it possible to study the effect of the nanoparticle oxide core size on solid state reactions in a wide temperature range. Meanwhile, for $\mathrm{TiO}_{2}$, carbothermal reduction starts already at $800{ }^{\circ} \mathrm{C}$. Above this temperature, the $\mathrm{TiO}_{2} @ \mathrm{C}$ core-shell structure is destroyed, and non-stoichiometric titanium oxide phases are formed.

High-temperature treatment of aluminum-containing oxide systems Oxide@C (above $1100-1200{ }^{\circ} \mathrm{C}$ ) gives a unique possibility to synthesize relatively dispersed oxide materials that do not contain structural water. Synthesis of such materials under conventional conditions is practically impossible because intense sintering of the samples and the accompanying phase transformations take place in this temperature range.

Electron paramagnetic resonance (EPR) is an excellent method for characterization of various active sites present of the surface of oxides, which can generate radical or ion-radical species after adsorption of suitable spin probes [13-16]. Electron-donor sites on such oxide supports as $\mathrm{Al}_{2} \mathrm{O}_{3}, \mathrm{MgO}, \mathrm{ZrO}_{2}$, etc. can be studied using aromatic nitro compounds due to their pronounced electron-acceptor properties, leading to the formation of stable radical anions $[17,18]$. Various aromatic donor molecules can be used to characterize electron-acceptor sites on the surface of a great variety of oxide materials, which can generate radical cations by abstracting a single electron from them $[15,16,19]$. The strength of the surface acceptor sites can be qualitatively characterized by selecting probe molecules with different ionization potentials [16].

The goal of this study was to compare high-temperature transformations of several oxide and core-shell structures based on them and determine the effect of the oxide nanoparticles size on their chemical transformations. 
Special attention was paid to characterization of the active sites on the surface of $\mathrm{Al}_{2} \mathrm{O}_{3}$ and $\mathrm{C} 12 \mathrm{~A} 7$ materials that are important for their application as supports for catalyst synthesis.

\section{Experimental}

The following materials were used as the main objects in this study. Nanocrystalline alumina $\left(\mathrm{AP}^{-} \mathrm{Al}_{2} \mathrm{O}_{3}\right)$ was prepared using the aerogel technique described in detail elsewhere [20,21]. A $\gamma-\mathrm{Al}_{2} \mathrm{O}_{3}$ sample $\left(\mathrm{SB} 1-\mathrm{Al}_{2} \mathrm{O}_{3}\right)$ prepared by decomposition of Condea Pural SB1 pseudoboehmite was studied for comparison. Before deposition of the carbon coating, the samples were calcined in a muffle furnace in air at $720{ }^{\circ} \mathrm{C}$ for $6 \mathrm{~h}$. The specific surface area of the used samples was $\sim 200 \mathrm{~m}^{2} / \mathrm{g}$.

Hydrated zirconia samples with the surface area $\sim 300 \mathrm{~m}^{2} / \mathrm{g}$ were prepared by traditional precipitation from a $\mathrm{ZrOCl}_{2}$ solution with ammonia at $\mathrm{pH}=10.6$. The precipitate was washed with a water excess until neural $\mathrm{pH}$. The obtained sample was dried at $110{ }^{\circ} \mathrm{C}$ for $12 \mathrm{~h}$ and was not subjected to any heat treatment before deposition of the carbon coating.

A mixture of aluminum hydroxide (Condea Pural SB1 pseudoboehmite) and calcium hydroxide with the required stoichiometric ratio was used as a precursor for $\mathrm{C} 12 \mathrm{~A} 7$ synthesis. The mixture was thoroughly stirred in distilled water for $10 \mathrm{~h}$, filtered and dried at $110{ }^{\circ} \mathrm{C}$. Then it was calcined in a muffle furnace in air at $550{ }^{\circ} \mathrm{C}$ for $6 \mathrm{~h}$. The obtained C12A7-550 sample was used as a starting material for further synthesis.

Core-shell materials were prepared by mixing each oxide powder with polyvinylalcohol (PVA) in the weight ratio $7: 3$ followed by calcination of the obtained mixture in argon at desired temperature typically for $6 \mathrm{~h}$. The carbon-coated samples will be hereafter denoted as Oxide@C-T, where Oxide is the type of the oxide core, and $T$ is the final calcination temperature in ${ }^{\circ} \mathrm{C}$.

$\mathrm{LaAl}_{11} \mathrm{O}_{18}$ and $\mathrm{LaAlO}_{3}$ samples were synthesized by a modified Pechini route from ethylene glycol - citric ester polyester precursors [22]. After aerobic decomposition of the polymeric precursors $400{ }^{\circ} \mathrm{C}$, further calcination of the samples with preservation of the carbon shell was carried out under argon at $700-1300{ }^{\circ} \mathrm{C}$. So, the procedure used for synthesis of core-shell samples was different for this material. The samples without the carbon coating were calcined in air.

The EPR spectra were recorded at room temperature using an ERS-221 EPR spectrometer working in the X-band. The experimental installation was described in detail elsewhere [23]. 1,3,5-Trinitrobenzene (TNB), anthracene, phenothiazine and diphenylamine probes used to characterize various surface active sites were adsorbed from $20 \mathrm{mM}$ solutions in toluene. Prior to adsorption of the probe molecules, the samples were activated in air at $500{ }^{\circ} \mathrm{C}$ for $3 \mathrm{~h}$. The probe adsorption and spectrum recording procedure was reported in detail in our earlier publications $[16,18]$.

Specific surface areas determined by the BET method were calculated from the data obtained by lowtemperature argon adsorption using an ASAP-2400 instrument. XRD analysis was performed using a Brucker D8 diffractometer with Co $\mathrm{K} \alpha$ irradiation. High-resolution transmission electron microscopy images were obtained using a JEM-2010CX microscope with $1.4 \AA$ line resolution.

\section{Results and discussion}

\section{1. $\mathbf{A l}_{2} \mathbf{O}_{3} @ \mathbf{C}$}

$\gamma-\mathrm{Al}_{2} \mathrm{O}_{3}$ is widely used in chemical technology as a sorbent and a catalyst support. This compound preserves its phase composition and relatively high surface area $\left(200-300 \mathrm{~m}^{2} / \mathrm{g}\right)$ up to $700-800{ }^{\circ} \mathrm{C}$. At higher temperatures, it is subjected to dehydration and sintering of nanoparticles to form $\delta-\mathrm{Al}_{2} \mathrm{O}_{3}$ phase with typical surface area $100-$ $120 \mathrm{~m}^{2} / \mathrm{g}$. Further temperature increase is accompanied by the surface area drop to $1-5 \mathrm{~m}^{2} / \mathrm{g}$ with the formation of corundum $\left(\alpha-\mathrm{Al}_{2} \mathrm{O}_{3}\right)$ phase. Usually, this corresponds to complete alumina dehydration. It has been demonstrated that size effects play an important role in the phase transformations of this oxide [24-26]. The $\gamma-\mathrm{Al}_{2} \mathrm{O}_{3}$ phase is thermodynamically stable for samples with high specific surface area and the corresponding small particles size. Meanwhile, $\alpha-\mathrm{Al}_{2} \mathrm{O}_{3}$ is formed only after substantial growth of the oxide nanoparticles due to their sintering caused by the presence of direct contacts between the nanoparticles. Deposition of any shell eliminating such contacts favors the particle size stabilization and, as result, prevents the corundum phase formation and dehydration of catalytic materials. Earlier, we demonstrated that the size of the oxide core can be stabilized for various oxide nanoparticles in core-shell structures Oxide@C after deposition of the carbon coating on the surface. It is evident that the size of the starting oxide core, its morphology and the properties of the deposited carbon shell may have a significant effect on the thermal stability of such materials.

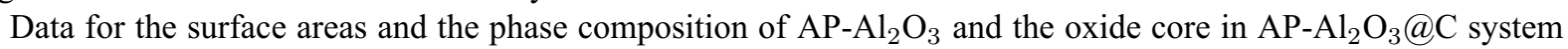
at high temperatures are shown in Figs 1 and 2. The presented data clearly demonstrate that complete conversion 
to corundum is not observed for $\mathrm{AP}-\mathrm{Al}_{2} \mathrm{O}_{3} @ \mathrm{C}$, even at temperatures as high as $1400{ }^{\circ} \mathrm{C}$. Meanwhile, the thermal stability of the low-temperature alumina phases in $\mathrm{SB} 1-\mathrm{Al}_{2} \mathrm{O}_{3} @ \mathrm{C}$ is substantially lower $[10,12]$.

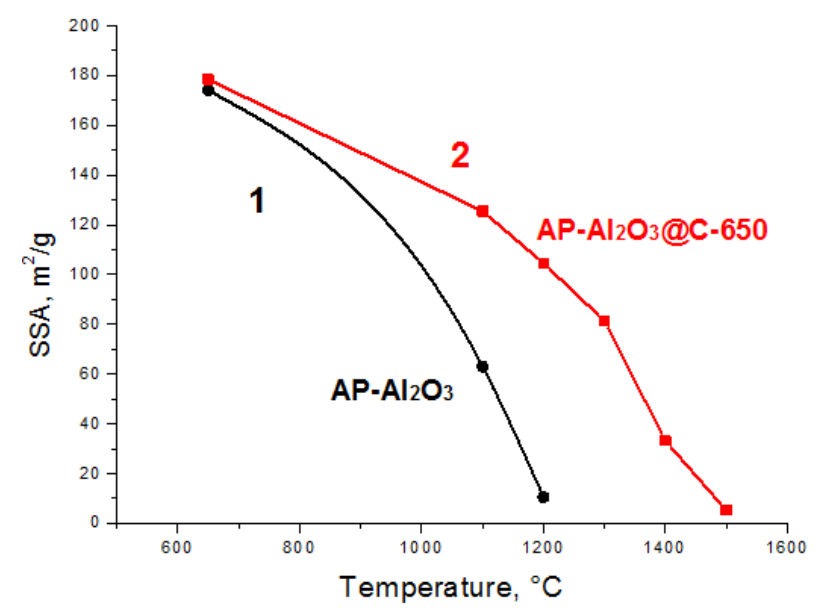

FIG. 1. Effect of calcination temperature on the surface area of $\mathrm{AP}-\mathrm{Al}_{2} \mathrm{O}_{3}$ (1) and $\mathrm{AP}-\mathrm{Al}_{2} \mathrm{O}_{3} @ \mathrm{C}$ sample after burning its carbon shell by calcination in air at (2)

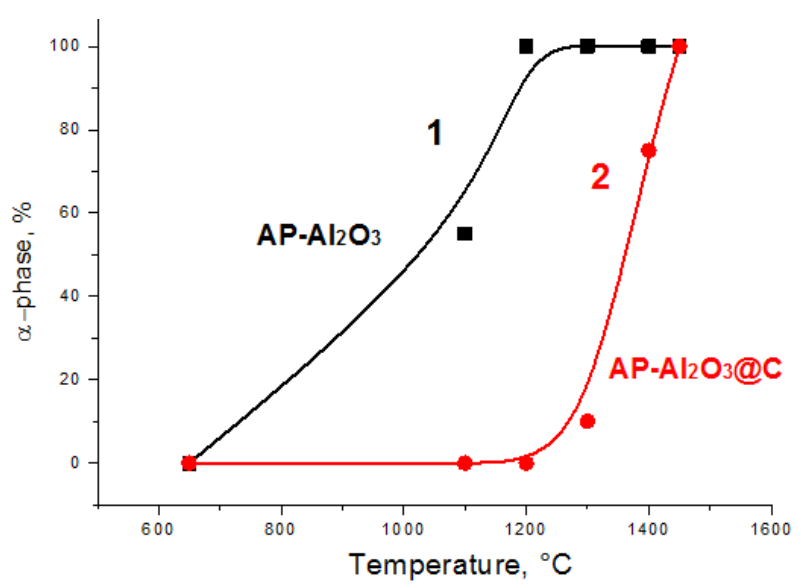

FIG. 2. Effect of calcination temperature on the corundum concentration in $\mathrm{AP}-\mathrm{Al}_{2} \mathrm{O}_{3}(1)$ and $\mathrm{AP}-\mathrm{Al}_{2} \mathrm{O}_{3} @ \mathrm{C}$

The evolution of Raman spectra of the carbon shell in $\mathrm{AP}-\mathrm{Al}_{2} \mathrm{O}_{3} @ \mathrm{C}$ at different calcination temperatures is presented in Fig. 3. Intense $G$ lines at $\sim 1590 \mathrm{~cm}^{-1}$ corresponding to allowed $E_{2 g}$ vibrations of the graphite hexagonal lattice and disorder-induced D lines attributed to activated $A_{1 g}$ mode due to the finite crystal size [27,28] at $\sim 1340 \mathrm{~cm}^{-1}$ were observed in the first-order scattering spectra of all $\mathrm{AP}-\mathrm{Al}_{2} \mathrm{O}_{3} @ \mathrm{C}$ samples. As the temperature increases, the $I_{D} / I_{G}$ ratio increases from 0.83 to 1.47 , and a second-order $2 \mathrm{D}$ line appears in the spectrum. A line at $\sim 864 \mathrm{~cm}^{-1}$, corresponding to the most intense $A_{1 \mathrm{~g}}$ line of $\mathrm{Al}_{4} \mathrm{C}_{4}$ appears in the spectrum of the sample calcined at $1500{ }^{\circ} \mathrm{C}$ [29]. Its appearance corresponds to the start of the oxide core carbothermal reduction to aluminum carbide.

As was noted above, a natural restriction on the highest temperature at which the oxide core size can be preserved for Oxide@C materials is the temperature of the chemical reaction between the shell and the core materials. Based on the presented data, we managed to approach this maximum temperature for $\mathrm{Al}_{2} \mathrm{O}_{3} @ \mathrm{C}$ using the $\mathrm{AP}-\mathrm{Al}_{2} \mathrm{O}_{3}$ core and our carbon shell deposition technique.

Alumina is a popular catalyst support. The presence of certain types of active sites on its surface is crucial for this application. So, we compared the concentrations of different active sites on the $\mathrm{Al}_{2} \mathrm{O}_{3}$ surface and on the surface of the $\mathrm{Al}_{2} \mathrm{O}_{3}$ core of $\mathrm{Al}_{2} \mathrm{O}_{3} @ \mathrm{C}$ calcined at high temperature after removing the carbon shell from them by calcination in air. 1,3,5-Trinitrobenzene adsorption was used for characterization of electron-donor sites [18]. 


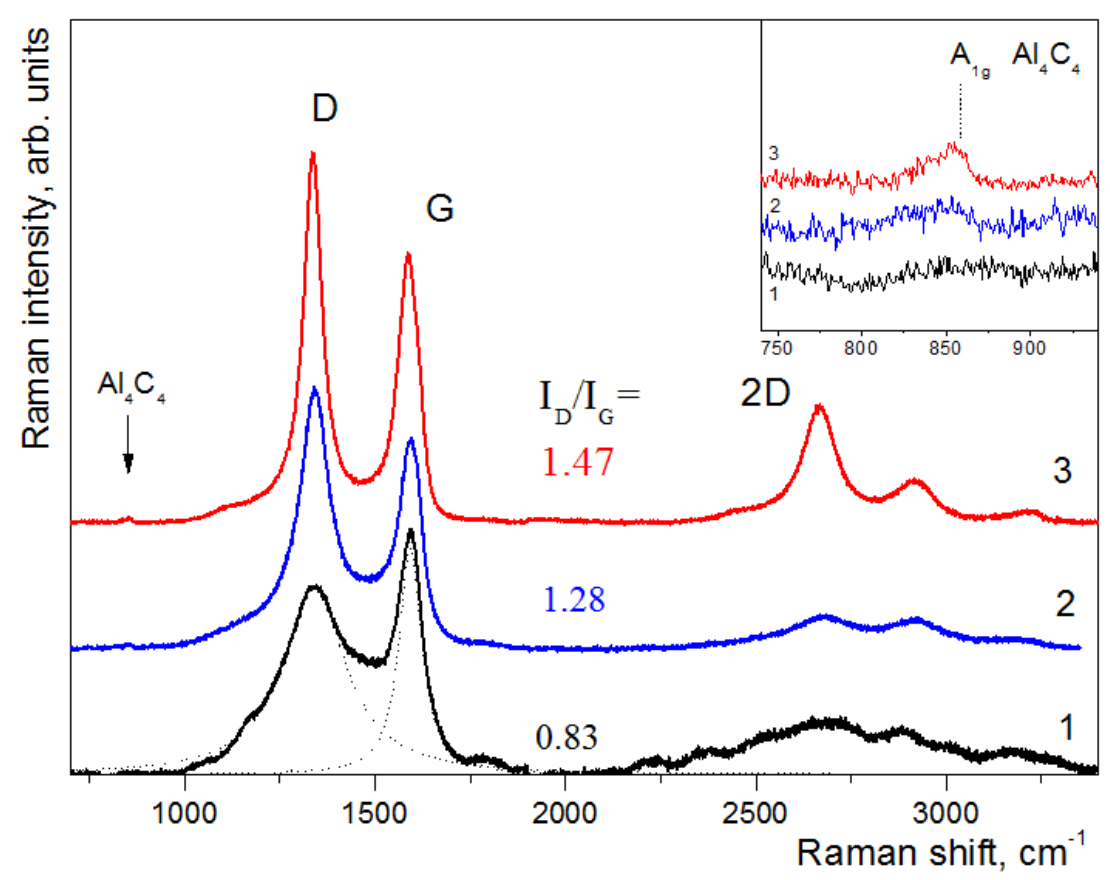

FIG. 3. Raman spectra of $\mathrm{AP}-\mathrm{Al}_{2} \mathrm{O}_{3} @ \mathrm{C}$ samples calcined in $\mathrm{Ar}$ at $650{ }^{\circ} \mathrm{C}(1), 1200{ }^{\circ} \mathrm{C}(2)$ and $1500{ }^{\circ} \mathrm{C}(3)$. Inset shows the section of the spectrum where the $\mathrm{A}_{1 \mathrm{~g}}$ line of $\mathrm{Al}_{4} \mathrm{C}_{4}$ is observed

Electron-acceptor sites were characterized using anthracene adsorption [30]. A $\delta-\mathrm{Al}_{2} \mathrm{O}_{3}$ sample obtained by aerobic calcination of $\mathrm{SB} 1-\mathrm{Al}_{2} \mathrm{O}_{3}$ sample at $1000{ }^{\circ} \mathrm{C}$ for $6 \mathrm{~h}$ was used as a reference.

Typical EPR spectra observed after adsorption of the probe molecules on the studied samples are shown in Fig. 4. The relative intensity of the signals reflects relative concentrations of electron-donor (Fig. 4A) and electronacceptor (Fig. 4B) sites. The presented results indicate that the properties of the active sites on the oxide core in $\mathrm{Al}_{2} \mathrm{O}_{3} @ \mathrm{C}$ are preserved, even after calcination at $1250{ }^{\circ} \mathrm{C}$, and their concentration correlates with the surface of the sample obtained after this treatment.

\section{2. $\mathrm{ZrO}_{2} @ \mathrm{C}$}

$\mathrm{ZrO}_{2}$ is another frequently used catalyst support. Depending on synthesis conditions and temperature, it can consist of cubic or monoclinic phase, or mixture of the two phases. The surface area dependence on the heattreatment temperature for samples $\mathrm{ZrO}_{2}, \mathrm{ZrO}_{2} @ \mathrm{C}$ and $\mathrm{ZrO}_{2} @ \mathrm{C}-600$ where the carbon coating was removed by $6 \mathrm{~h}$ calcination in air at $600{ }^{\circ} \mathrm{C}$ are shown in Fig. 5. The obtained results demonstrate a significant effect of the carbon coating on stabilization of the oxide core in $\mathrm{ZrO}_{2} @ \mathrm{C}$ system, similar to that observed for $\mathrm{Al}_{2} \mathrm{O}_{3} @ \mathrm{C}$. Comparison of the surface area of $\mathrm{ZrO}_{2} @ \mathrm{C}$ samples with that of the samples obtained after burning of the carbon shell in air (series $\mathrm{ZrO}_{2} @ \mathrm{C}$ and $\mathrm{ZrO}_{2} @ \mathrm{C}-600$ ) indicates a substantial contribution of the carbon coating to the surface area measured for $\mathrm{ZrO}_{2} @ \mathrm{C}$ samples. Still, preservation of the oxide core surface area $\left(\sim 20 \mathrm{~m}^{2} / \mathrm{g}\right.$ after calcination of the core-shell material at $1400{ }^{\circ} \mathrm{C}$ ) proves that the carbon coating assists in stabilization of the oxide core size. As in the case of alumina, the temperature range over which the cubic phase originally formed after synthesis is more stable in $\mathrm{ZrO}_{2} @ \mathrm{C}$ core-shell materials than in pure $\mathrm{ZrO}_{2}$ (Fig. 6). It correlates with the temperature range where relatively high surface area of the oxide is preserved.

\section{3. $\mathrm{LaAlO}_{3} @ \mathrm{C}$}

Lanthanum monoaluminate and hexaluminate are used as high-temperature catalyst supports. As the required phases of these materials are formed at high temperatures, synthesis of these materials with high specific surface area is quite complicated. Depending on the stoichiometry of the $\mathrm{La}_{2} \mathrm{O}_{3}-\mathrm{Al}_{2} \mathrm{O}_{3}$ system, either $\beta$-alumina structure $\mathrm{LaAl}_{11} \mathrm{O}_{18}$ is formed at $\mathrm{La} / \mathrm{Al}=8.3 \%$ or $\mathrm{LaAlO}_{3}$ with a perovskite structure at $\mathrm{La} / \mathrm{Al}=50 \%$. These phases have different temperature ranges of thermodynamic particle stability.

The formation of the $\mathrm{LaAlO}_{3}$ phases by the Pechini route takes place at $700{ }^{\circ} \mathrm{C}$ (Fig. 7). No other phases appear after the temperature increase. Only an amorphous phase containing residual carbon is observed in the $\mathrm{LaAlO}_{3} @ \mathrm{C}$ sample at the same temperature (Fig. 7). 

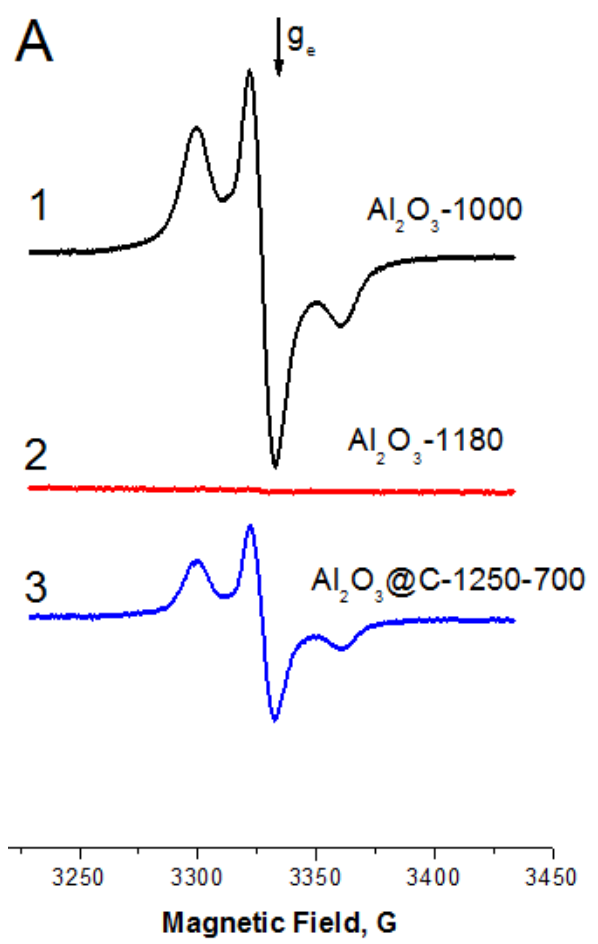
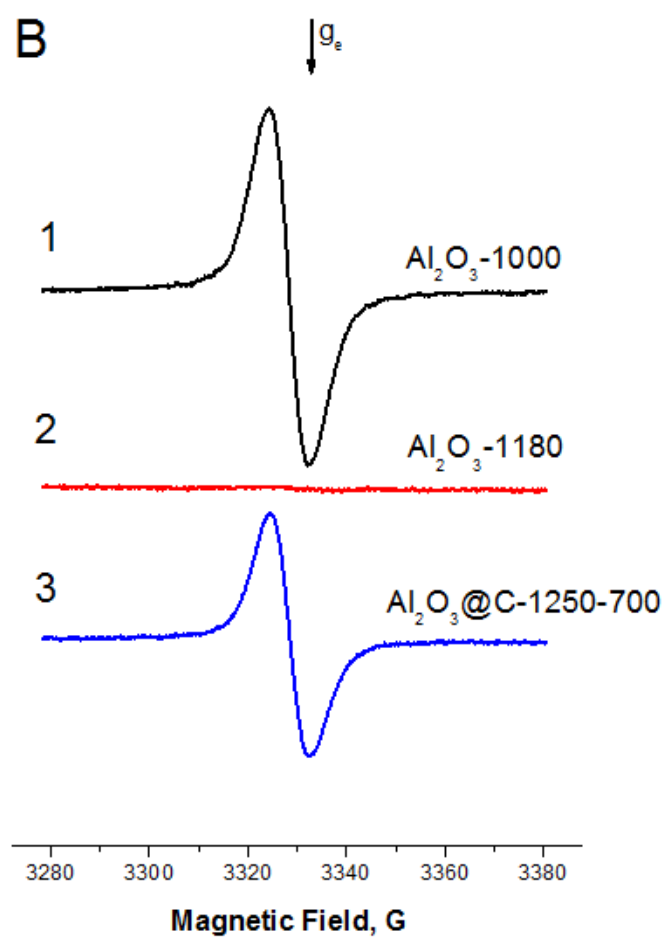

FIG. 4. EPR spectra of radicals registered after 1,3,5-trinitrobenzene (A) and anthracene (B) adsorption from toluene solution on $\mathrm{SB} 1-\mathrm{Al}_{2} \mathrm{O}_{3}-1000$ and $\mathrm{SB} 1-\mathrm{Al}_{2} \mathrm{O}_{3}-1180$ samples, and on the carbon-coated SB1- $\mathrm{Al}_{2} \mathrm{O}_{3} @ \mathrm{C}-1250$ sample after aerobic calcination at $700{ }^{\circ} \mathrm{C}$

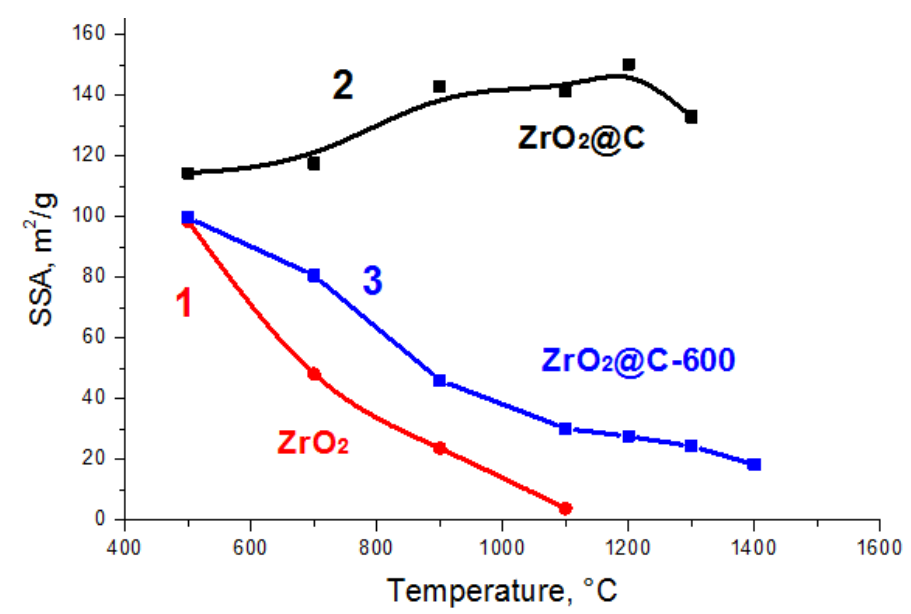

FIG. 5. Effect of calcination temperature on the surface area of $\mathrm{ZrO}_{2}$ (1), $\mathrm{ZrO}_{2} @ \mathrm{C}$ (2) and $\mathrm{ZrO}_{2} @ \mathrm{C}-600$ sample obtained by burning of the carbon coating in air at $600{ }^{\circ} \mathrm{C}(3)$

Preliminary experiments indicate that the presence of the carbon coating favors the formation of lanthanum hexaaluminate phase at temperatures above $1300{ }^{\circ} \mathrm{C}$. The most likely reason for this result is the preservation of relatively small oxide core particles in the presence of carbon introduced into the material during its synthesis via the Pechini route.

\subsection{C12A7@C}

Calcium aluminate materials with different stoichiometry have been well known for some time and thus extensively studied. They are essential constituents of various cements and are sometimes used as catalyst supports. The explosive growth of interest in one such material - calcium aluminate with $12 \mathrm{CaO}_{7} \mathrm{Al}_{2} \mathrm{O}_{3}$ composition, commonly denoted as $\mathrm{C} 12 \mathrm{~A} 7$, was inspired by the revelation of their unique chemical and electrophysical properties, 


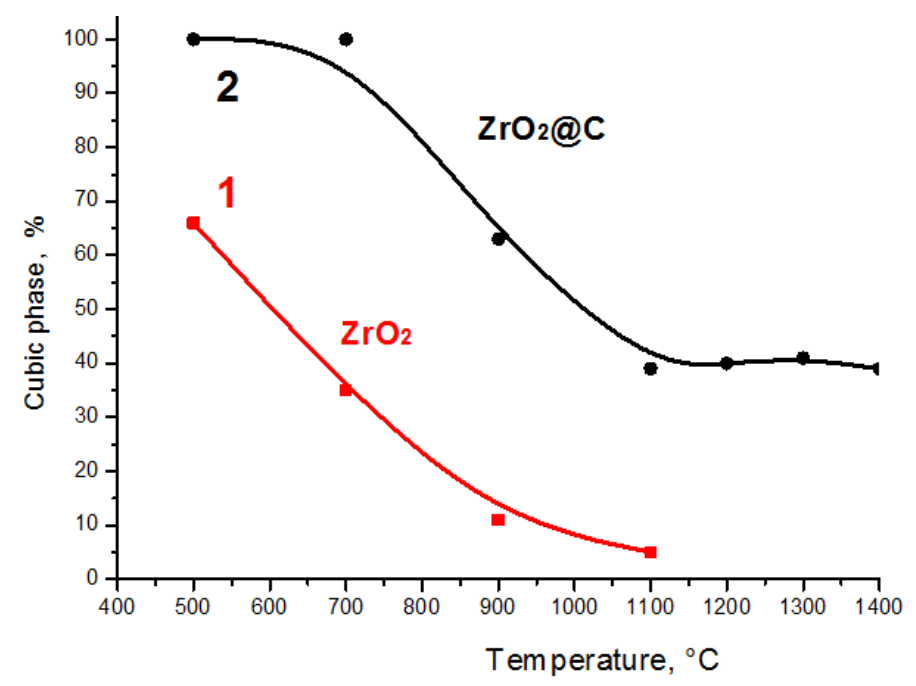

FIG. 6. Effect of calcination temperature cubic phase fraction in $\mathrm{ZrO}_{2}$ (1) and $\mathrm{ZrO}_{2} @ \mathrm{C}$ (2)

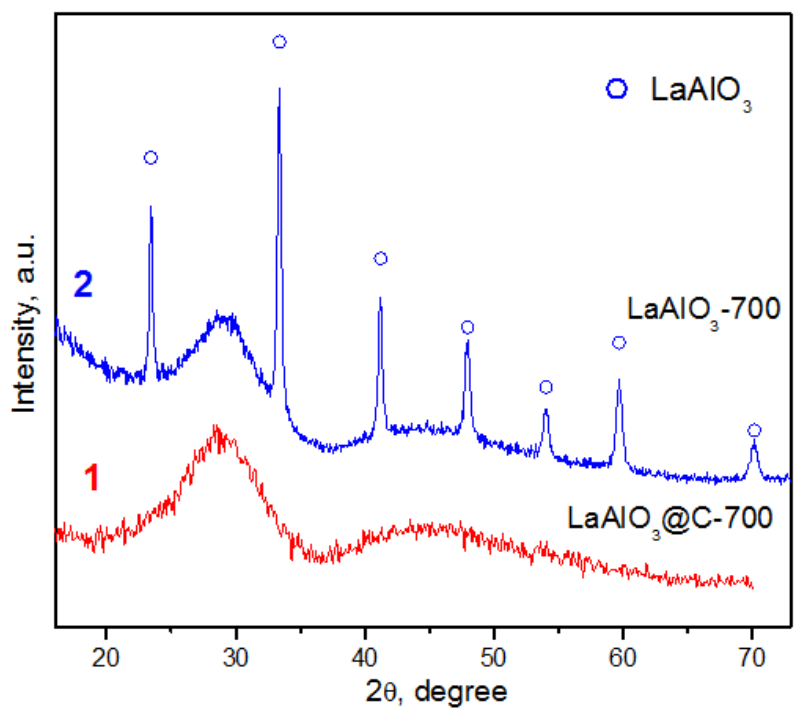

FIG. 7. XRD patterns of the $\mathrm{LaAlO}_{3} @ \mathrm{C}-700$ samples calcined at $700{ }^{\circ} \mathrm{C}$ in $\arg$ on (1) and in air (2)

discovered and thoroughly investigated by Hosono et al. [31-34]. They contain a stable cationic framework $\left[\mathrm{Ca}_{24} \mathrm{Al}_{28} \mathrm{O}_{64}\right]^{4+}$ and relatively mobile anionic sublattice $4 \mathrm{X}^{-}$. The chemical and electrophysical properties of such materials can be varied over a wide range by altering the $\mathrm{X}^{-}$anions. Their elementary cell can be written by the following formula:

$$
1 \text { unit cell }=\left[\mathrm{Ca}_{24} \mathrm{Al}_{28} \mathrm{O}_{64}\right]^{4+} .4 \mathrm{X}^{-}, \text {where } \mathrm{X}^{-}=\mathrm{H}^{-}, \mathrm{O}^{-}, \mathrm{O}_{2}^{-}, \mathrm{O}^{2-}, \mathrm{OH}^{-}, \mathrm{Cl}^{-}, \mathrm{F}^{-}, \mathrm{e}^{-} \text {. }
$$

Especially interesting among this list are electrides - materials with $\mathrm{X}^{-}=\mathrm{e}^{-}$. These materials have metal conductivity, unique emission, optical and chemical properties. However, their synthesis requires temperatures as high as $1600{ }^{\circ} \mathrm{C}$, making it very difficult to prepare these materials in a finely dispersed form. Note that C12A7:e is the only bulk inorganic electride known to date.

Structural and electrophysical features of the electride phase formation in the carbon nanoreactor conditions in C12A7@C system have been described in detail in one of our recent publications $[11,35,36]$. One of the main obtained results is that we managed to stabilize the size of the oxide core in C12A7@C at $\sim 100 \mathrm{~nm}$, even at temperatures substantially exceeding the C12A7 melting point $\left(1415^{\circ} \mathrm{C}\right)$. The small particle size substantially facilitates diffusion process in this material making it possible to decrease the temperatures required for migration of anions and electride formation. 
The XRD data presented in Fig. 8 demonstrate that dispersed C12A7 phase can be synthesized in C12A7@C using the procedure described in the Experimental section starting from temperatures as low as $500-600{ }^{\circ} \mathrm{C}$.

However, even after the formation of the electride state at $1380{ }^{\circ} \mathrm{C}$, the size of the oxide core in such material is preserved in the range of $100-150 \mathrm{~nm}$. Fig. 9 presents an HRTEM image of a typical particle of such material. Several graphene layers can be observed on the particle surface.
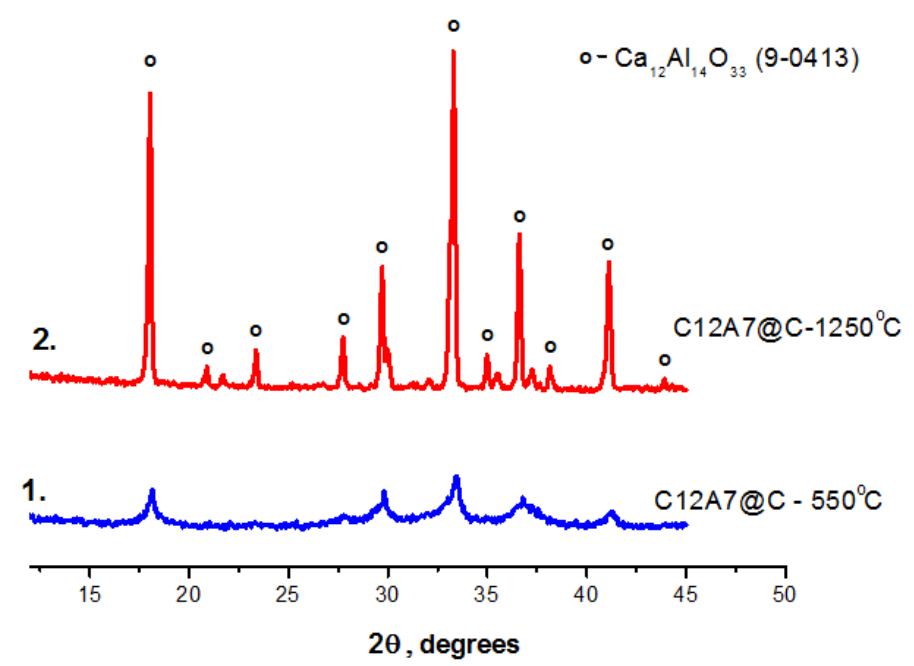

FIG. 8. XRD patterns of C12A7@C samples after calcination at different temperatures in argon flow

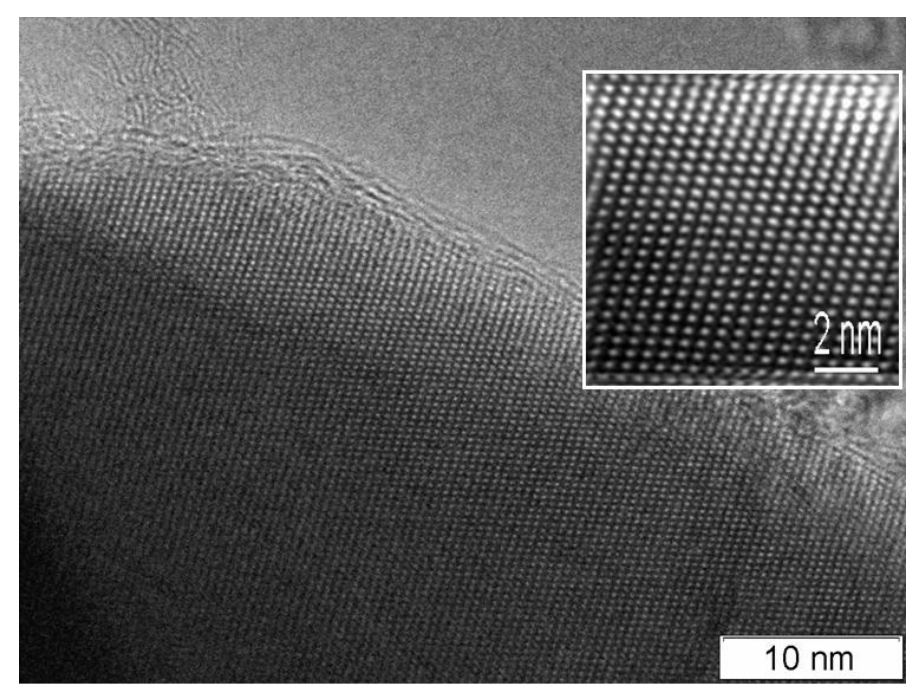

FIG. 9. HRTEM image of C12A7@C sample after calcination at $1380{ }^{\circ} \mathrm{C}$ under argon. The inset shows a section of the image after Fourier filtration

One possible application for finely dispersed C12A7 materials is their use in catalytic and adsorption technologies. Therefore, it was important to incorporate various active sites on their surface. No such information was available in the literature before this study.

EPR spectra observed after adsorption of TNB, phenothiazine and diphenylamine from toluene solutions on C12A7-600 (A) and $\mathrm{Al}_{2} \mathrm{O}_{3}-720$ (B) samples activated at $500{ }^{\circ} \mathrm{C}$ are presented in Fig. 10. The alumina sample prepared using the same precursor was chosen as a reference sample because $\mathrm{C} 12 \mathrm{~A} 7$ contains a substantial amount of alumina, whereas electron-donor and electron-sites on the alumina surface have been extensively characterized previously $[16,18,30]$. Although the surface area of C12A7-600 was lower than that of the alumina sample (80 vs. $200 \mathrm{~m}^{2} / \mathrm{g}$ ), it is sufficiently high for its application as a catalyst support.

All the used probe molecules have nitrogen atoms, and their EPR spectra feature 3-component signals due to hyperfine splitting on a nitrogen atom with $S=1$ with frozen rotation. The spectrum observed after TNB 

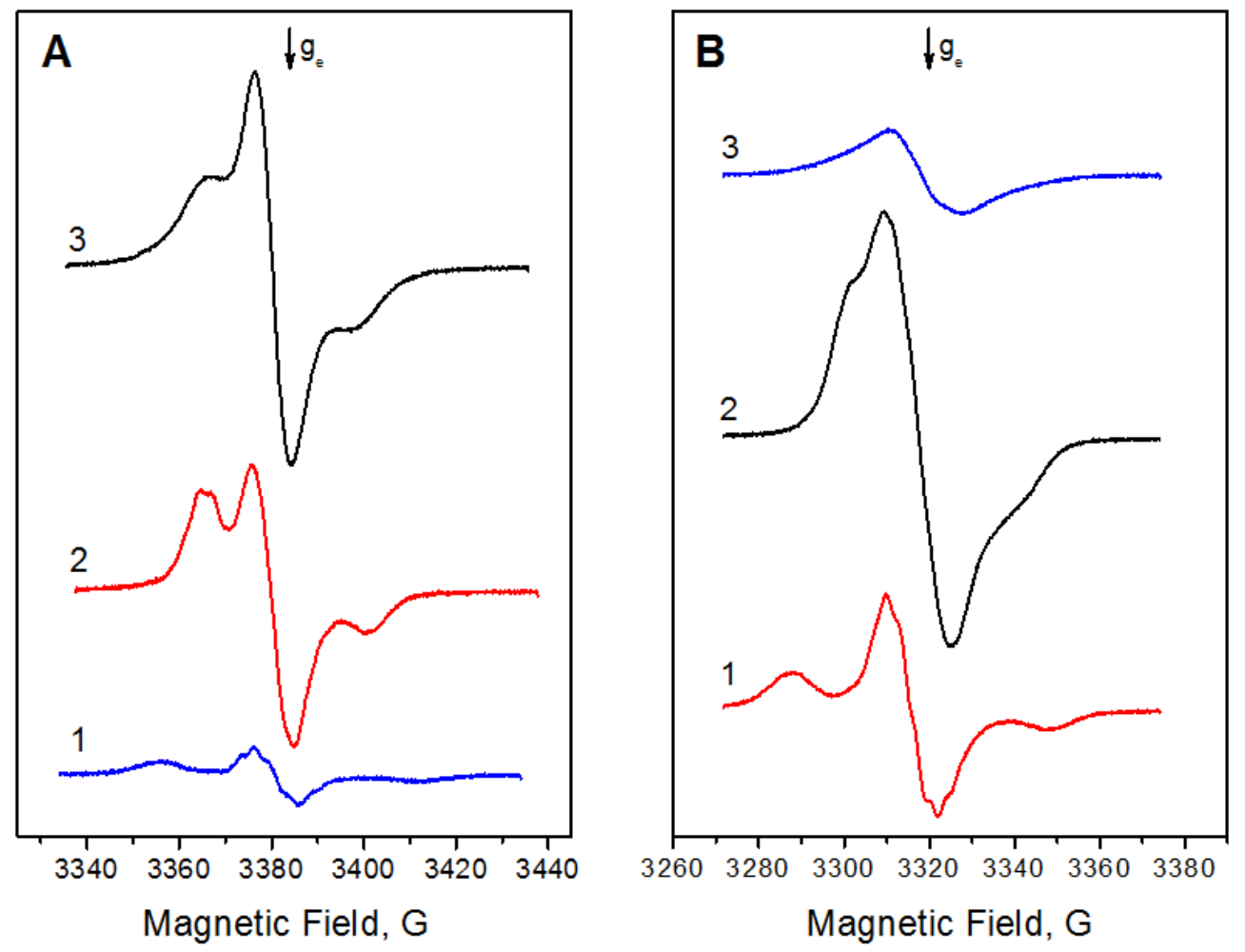

FIG. 10. EPR spectra observed on the surface of $\mathrm{C} 12 \mathrm{~A} 7-600$ (A) and $\mathrm{Al}_{2} \mathrm{O}_{3}-720$ (B) activated at $500{ }^{\circ} \mathrm{C}$ after adsorption of 1,3,5-trinitrobenzene (1), phenothiazine (2) and diphenylamine (3) from toluene solutions

adsorption on C12A7-600 is similar to the one observed after TNB adsorption on alumina with somewhat smaller $A_{z z}\left(27 \mathrm{G}\right.$ vs. $30 \mathrm{G}$ on $\left.\mathrm{Al}_{2} \mathrm{O}_{3}\right)$. It was previously attributed to TNB radical anion forming an ion par with an aluminum cation [18]. This means that the studied C12A7-600 also has electron-donor sites of the same type as those present on the $\mathrm{Al}_{2} \mathrm{O}_{3}$ surface. However, their concentration was ca. 8.5-fold lower than on the reference alumina sample when normalized to the sample weight or about 3.5-fold lower when normalized to the surface area.

Phenothiazine has very low ionization potential of approximately $6.8 \mathrm{eV}$; as a result, it can be used for characterization of very weak electron-acceptor sites. Its adsorption on $\mathrm{Al}_{2} \mathrm{O}_{3}$ results in the appearance of a poorly-resolved three-component spectrum with $A_{z z}=20 \mathrm{G}$ attributable to its radical cations. On C12A7-600, the spectrum resolution was much better, with slightly smaller hyperfine constant $(18 \mathrm{G})$, whereas the spectrum intensity, when normalized to the surface area, was approximately the same. So, C12A7-600 has weak electronacceptor sites on its surface, and their concentration is approximately the same as on the $\mathrm{Al}_{2} \mathrm{O}_{3}$ surface.

Diphenylamine also has low ionization potential, equal to $7.2 \mathrm{eV}$ and can be ionized to its radical cations on the surface of many acidic materials that have electron-acceptor sites. Apparently, this is what happens after its adsorption on $\mathrm{Al}_{2} \mathrm{O}_{3}-720$, where a wide unresolved spectrum is observed. It resembles the one earlier reported after diphenylamine on H-ZSM-5 zeolite [37] where it was attributed to a mixture of primary diphenylamine radical cations and products of their transformations.

However, in solution, diphenylamine is well known to form quite stable diphenyloxyl nitroxyl radicals in the presence of peroxides, apparently, due to reaction with hydroxyls resulting from their decomposition. The spectrum observed after diphenylamine adsorption on the surface of C12A7-600 is a triplet with $A_{z z}=16 \mathrm{G}$, which can be attributed to diphenyloxyl nitroxyl radicals adsorbed onto its surface. Remarkably, their concentration normalized to the surface area exceeded the concentration of radical species observed on the $\mathrm{Al}_{2} \mathrm{O}_{3}-720$ sample by roughly 3 -fold. This means that the surface of activated $\mathrm{C} 12 \mathrm{~A} 7$ has a significant concentration of active $\mathrm{OH}$ radicals. It seems to be a specific feature of this material related to its unique structure that merits further investigation, as we did not observe similar signals on other oxide materials that we studied. 


\section{Conclusion}

It has been demonstrated that it is possible to stabilize dimensions of oxide nanoparticles with different chemical composition and prevent their sintering at high temperatures by depositing a carbon coating on their surface. Such approach appears to be fairly universal and can be used for various oxide materials in a wide temperature range below the temperature of the oxide core carbothermal reduction. The carbon coating prevents direct contact between the oxide nanoparticles, thus, preventing their sintering. Before our studies, possible effects of the particle size on the thermodynamic stability of different phases of $\mathrm{TiO}_{2}$ (anatase-rutile) and $\mathrm{Al}_{2} \mathrm{O}_{3}(\mathrm{gamma}$, delta and alpha phases) were known. For $\mathrm{TiO}_{2} @ \mathrm{C}$ and $\mathrm{Al}_{2} \mathrm{O}_{3} @ \mathrm{C}$, the low-temperature phases of the oxide core could be preserved up to the temperature where they reacted with their carbon shell. So, for $\mathrm{TiO}_{2} @ \mathrm{C}$ the anatase phase is stable to $800{ }^{\circ} \mathrm{C}$. Above this temperature, the carbon shell is destroyed, and non-stoichiometric titanium oxide phases are formed. For $\mathrm{Al}_{2} \mathrm{O}_{3} @ \mathrm{C}$ the corundum phase is formed only at temperatures above $1400{ }^{\circ} \mathrm{C}$, when decomposition of the carbon shell due to its interaction with the oxide core material begins. Based on the results obtained in this study for zirconium oxide and lanthanum aluminate, the carbon shell also can stabilize both the size and phase composition.

The data presented for the C12A7@C material exemplify the possibility of stabilizing the size of the oxide core, even above its melting temperature. Apparently the carbon shell prevents interaction between the droplets of the melted oxide core. Meanwhile, the carbon coating synthesized using the reported procedure appears to be permeable for molecules of the gas phase. This makes it possible to perform synthesis of new solid products by reaction of the oxide core material with gaseous reagents.

Carbon coating is only one of several possible variations of a nanoreactor shell for oxide nanoparticles. Such shell is not always inert, as is shown in carbothermal reduction processes. Also it is absolutely inapplicable for reactions at high temperatures in the presence of oxygen. The search of other materials that could function as such nanoreactor where similar processes could be carried out in the presence of air is important for many practical applications. One possible approach to creating air-stable materials with an oxide core is the synthesis of core-shell structures with an oxide shell. The first results we obtained using such shells as $\mathrm{SiO}_{2}$ and $\mathrm{MgO}$ for this purpose seemed to be promising.

\section{Acknowledgements}

This study was supported by Russian Science Foundation, Project 16-13-10168.

\section{References}

[1] Park J.C., Bang J.U., et al. Ni@ $\mathrm{SiO}_{2}$ yolk-shell nanoreactor catalysts: High temperature stability and recyclability. J. Mater. Chem., 2010, 20 (7), P. 1239-1246.

[2] Chaudhuri R.G., Paria S. Core/Shell Nanoparticles: Classes, Properties, Synthesis Mechanisms, Characterization, and Applications. Chem. Rev., 2012, 112 (4), P. 2373-2433.

[3] Yang W.L., Wang Y.R., et al. Carbon nanocoating: an effective nanoreactor towards well-defined carbon-coated GaN hollow nanospindles. Nanoscale, 2014, 6 (6), P. 3051-3054.

[4] Plumejeau S., Alauzun J.G., Boury B. Hybrid metal oxide@biopolymer materials precursors of metal oxides and metal oxide-carbon composites. J. Ceram. Soc. Jpn., 2015, 123 (1441), P. 695-708.

[5] Li B., Nam H., et al. Nanoreactor of Nickel-Containing Carbon-Shells as Oxygen Reduction Catalyst. Adv. Mater., 2017, 29 (7), 1605083.

[6] Lee J., Kim S.M., Lee I.S. Functionalization of hollow nanoparticles for nanoreactor applications. Nano Today, 2014, 9 (5), P. $631-667$.

[7] Bedilo A.F., Sigel M.J., et al. Synthesis of carbon-coated MgO nanoparticles. J. Mater. Chem., 2002, 12 (12), P. 3599-3604.

[8] Bedilo A.F., Shuvarakova E.I., et al. Effect of Modification with Vanadium or Carbon on Destructive Sorption of Halocarbons over Nanocrystalline MgO: The Role of Active Sites in Initiation of the Solid-State Reaction. J. Phys. Chem. C, 2014, 118 (25), P. 1371513725.

[9] Yakovlev I.V., Volodin A.M., et al. Stabilizing effect of the carbon shell on phase transformation of the nanocrystalline alumina particles. Ceram. Int., 2018, 44 (5), P. 4801-4806.

[10] Volodin A., Bedilo A.F., et al. Nanocrystalline carbon coated alumina with enhanced phase stability at high temperatures. RSC Adv., 2017, 7 (86), P. 54852-54860.

[11] Volodin A.M., Zaikovskii V.I., et al. Synthesis of nanocrystalline calcium aluminate C12A7 under carbon nanoreactor conditions. Mater. Lett., 2017, 189, P. 210-212.

[12] Volodin A.M., Bedilo A.F., et al. Carbon nanoreactor for the synthesis of nanocrystalline high-temperature oxide materials. Nanotechnologies in Russia, 2014, 9 (11), P. 700-706.

[13] Flockhart B.D., Leith I.R., Pink R.C. Evidence for the redox nature of the surface of catalytic aluminas. J. Catal., 1967, 9 (1), P. $45-50$.

[14] Garcia H., Roth H.D. Generation and reactions of organic radical cations in zeolites. Chem. Rev., 2002, 102 (11), P. $3947-4007$.

[15] Bedilo A.F., Volodin A.M. Radical cations of aromatic molecules with high ionization potentials on the surfaces of oxide catalysts: Formation, properties, and reactivity. Kinet. Catal., 2009, 50 (2), P. 314-324.

[16] Bedilo A.F., Shuvarakova E.I., Rybinskaya A.A., Medvedev D.A. Characterization of Electron-Donor and Electron-Acceptor Sites on the Surface of Sulfated Alumina Using Spin Probes. J. Phys. Chem. C, 2014, 118 (29), P. 15779-15794. 
[17] Flockhart B.D., Leith I.R., Pink R.C. Electron-transfer at alumina surfaces. Part 3 - Reduction of aromatic nitro-compounds. Trans. Faraday Soc., 1970, 66, P. 469-476.

[18] Medvedev D.A., Rybinskaya A.A., et al. Characterization of electron donor sites on $\mathrm{Al}_{2} \mathrm{O}_{3}$ surface. Phys. Chem. Chem. Phys., 2012, 14 (8), P. 2587-2598.

[19] Shuvarakova E.I., Bedilo A.F., Chesnokov V.V., Kenzhin R.M. Dehydrochlorination of 1-Chlorobutane Over Nanocrystalline MgO: The Role of Electron-Acceptor Sites. Top Catal., 2018, In Press, DOI: 10.1007/s11244-018-1000-8.

[20] Khaleel A.A., Klabunde K.J. Characterization of aerogel prepared high-surface-area alumina: In situ FTIR study of dehydroxylation and pyridine adsorption. Chem. Eur. J., 2002, 8 (17), P. 3991-3998.

[21] Carnes C.L., Kapoor P.N., Klabunde K.J., Bonevich J. Synthesis, characterization, and adsorption studies of nanocrystalline aluminum oxide and a bimetallic nanocrystalline aluminum oxide/magnesium oxide. Chem. Mater, 2002, 14 (7), P. $2922-2929$.

[22] Sadykov V., Usoltsev V., et al. Functional nanoceramics for intermediate temperature solid oxide fuel cells and oxygen separation membranes. J. Eur. Ceram. Soc., 2013, 33 (12), P. 2241-2248.

[23] Bolshov V.A., Volodin A.M., et al. Radical Intermediates in the Photoinduced Formation of Benzene Cation-Radicals Over H-Zsm-5 Zeolites. J. Phys. Chem., 1994, 98 (31), P. 7551-7554.

[24] Mchale J.M., Auroux A., Perrotta A.J., Navrotsky A. Surface energies and thermodynamic phase stability in nanocrystalline aluminas. Science, 1997, 277 (5327), P. 788-791.

[25] Castro R.H.R., Ushakov S.V., et al. Surface energy and thermodynamic stability of gamma-alumina: Effect of dopants and water. Chem. Mater, 2006, 18 (7), P. 1867-1872.

[26] Castro R.H.R. On the thermodynamic stability of nanocrystalline ceramics. Mater. Lett., 2013, 96, P. 45-56.

[27] Ferrari A.C., Robertson J. Interpretation of Raman spectra of disordered and amorphous carbon. Phys. Rev. B, 2000, 61 (20), P. 1409514107.

[28] Tuinstra F., Koenig J.L. Raman Spectrum of Graphite. J. Chem. Phys., 1970, 53 (3), P. 1126-1130.

[29] Kennedy J.L., Drysdale T.D., Gregory D.H. Rapid, energy-efficient synthesis of the layered carbide, $\mathrm{Al}_{4} \mathrm{C}_{3} . \mathrm{Green}_{\mathrm{C}}$ Chem., 2015 , 17 (1), P. 285-290.

[30] Zotov R.A., Molchanov V.V., Volodin A.M., Bedilo A.F. Characterization of the active sites on the surface of $\mathrm{Al}_{2} \mathrm{O}_{3}$ ethanol dehydration catalysts by EPR using spin probes. J. Catal., 2011, 278 (1), P. 71-77.

[31] Hayashi K., Matsuishi S., Kamiya T., Hirano M. Light-induced conversion of an insulating refractory oxide into a persistent electronic conductor. Nature, 2002, 419 (6906), P. 462-465.

[32] Matsuishi S., Toda Y., et al. High-density electron anions in a nanoporous single crystal, $\left[\mathrm{Ca}_{24} \mathrm{Al}_{28} \mathrm{O}_{64}\right]^{4+} 4 \mathrm{e}^{-}$. Science, $2003, \mathbf{3 0 1}(5633)$, P. 626-629.

[33] Kitano M., Inoue Y., et al. Ammonia synthesis using a stable electride as an electron donor and reversible hydrogen store. Nature Chem., 2012, 4 (11), P. 934-940.

[34] Kim S.W., Hosono H. Synthesis and properties of $12 \mathrm{CaO} 7 \mathrm{Al}_{2} \mathrm{O}_{3}$ electride: review of single crystal and thin film growth. Philosophical Magazine, 2012, 92 (19-21), P. 2596-2628.

[35] Yakovlev I.V., Volodin A.M., et al. Structure of Carbon-Coated C12A7 Electride via Solid-State NMR and DFT Calculations. J. Phys. Chem. C, 2017, 121 (40), P. 22268-22273.

[36] Zaikovskii V.I., Volodin A.M., et al. Effect of carbon coating on spontaneous C12A7 whisker formation. Appl. Surf. Sci., 2018, 444, P. 336-338.

[37] Garcia H., Marti V., et al. Generation and conversions of aromatic amine radical cations in acid zeolites. Phys. Chem. Chem. Phys., 2001, 3 (14), P. 2955-2960. 